\title{
Modification in Atmospheric Refractivity and GPS Based TEC as Earthquake Precursors
}

\author{
Sheetal P. Karia*, Kamlesh N. Pathak, Kunvar S. Yadav, Nikita P. Chaudhary, \\ Nilesh C. Patel. Ranjan Jana \\ Applied Physics Department, S. V. National Institute of Technology, Surat, India \\ Email: ${ }^{*}$ sheetalkaria1@gmail.com
}

Received 5 March 2014; revised 5 April 2014; accepted 2 May 2014

Copyright (C) 2014 by authors and Scientific Research Publishing Inc. This work is licensed under the Creative Commons Attribution International License (CC BY). http://creativecommons.org/licenses/by/4.0/

(c) $\underset{\mathrm{EY}}{\mathrm{O}}$ Open Access

\section{Abstract}

The present paper reports the modification in GPS TEC (total electron content) and atmospheric refractivity prior to the Iran earthquake that had occurred on 16 April 2013 in Iran (28.10 $\mathrm{N}$, $\left.62.05^{\circ} \mathrm{E}\right)$. The analysis of GPS-based TEC from two GPS receivers, Surat $\left(21.16^{\circ} \mathrm{N}, 72.78^{\circ} \mathrm{E}\right)$ and $^{\circ}$ Lucknow $\left(26.91^{\circ} \mathrm{N}, 80.95^{\circ} \mathrm{E}\right)$ and results of atmospheric refractivity profile for radiosonde observation stations (Shiraz, Iran and Delhi, India) around the fault line are presented in this paper. It is seen that atmospheric refractivity gets modified from 8 to 6 days prior to the earthquake at Shiraz, Iran and Delhi, India. The GPS TEC showed variations a few days prior to the earthquake. We conclude that in search of precursory signatures for an earthquake, both GPS TEC and refractivity are important parameters.

\section{Keywords}

Total Electron Content, Refractivity, Earthquake

\section{Introduction}

A major earthquake $(M=7.8)$ struck Iran near the border with Pakistan on 16 April 2013 at 10:44 GMT. Tremors from this earthquake were also felt in India. This made us do some intriguing research about whether large earthquakes are associated with ionospheric/atmospheric changes caused due to earthquake preparation above the epicenter or throughout the fault line. If so, then this might be useful in identifying precursory signature. Variations in ground, atmosphere and space parameters have been studied by many. Some of them have shown

${ }^{*}$ Corresponding author. 
[1] [2] that studying atmospheric variability could also reveal active tectonic processes in the Earth's crust. The atmospheric refractivity is proportional to the pressure and temperature gradient of the troposphere. With respect to the earthquake preparation the vertical profiles of humidity, pressure and temperature are changed. These variations in the local parameters cause the atmospheric refractivity to change and can potentially affect the ray path of any electromagnetic wave. It is evident from [3]-[8] that seismic events affect the local atmosphere and the ionospheric parameters. The variation in ionospheric TEC (total electron content) prior to an earthquake is conducted by many researchers from above references. The GPS signal propagating through the ionosphere is enhanced in phase and delayed in time. This time delay being a function of electron density when measured by using a dual frequency receiver can compute the TEC (the total of no electron encountered along a particular line-of sight by the propagating wave). From the difference between the two-frequency measurements, the TEC along the signal path between GPS and the receiver can be calculated. Unit of TEC is $10^{16}$ per square meter. The TEC is variable in space and time and is a function of local time season and geomagnetic latitude.

Research of seismogenic-origin anomalous effects in different ionospheric parameters has been carried out in the past decade by [2] [7] [9], stress-activated positive hole charge carriers in rocks and the generation of preearthquake signals. Freund 2000 [10] has provided the reason for enlargement in the scope of research in this field. Examination of the validity of the preseismic anomalous transmission of very high frequency (VHF) electromagnetic waves beyond the line of sight was originally proposed by Kushida and Kushida [11] in Japan. Fujiwara et al. [12] statistically demonstrated the existence of atmospheric anomalies lasting for a few minutes to several hours before earthquakes. Fujiwara and colleagues monitored the VHF waves (FM radio; around 80 megahertz) in eastern Tokyo that were transmitted from an over-the horizon radio station in northern Honshu, and thoroughly compared the waves with the seismicity in the surrounding regions. They found that the transmission anomalies were significantly enhanced within five days prior to $M \geq 4.8$ earthquakes. Increase in propagation horizon of VHF has been reported and the role of seismic effect on the refractive index has been examined to explain the observed TEC features for some earthquakes recently [8] [13].

In the present report, the TEC profile is obtained for the period prior to and after the earthquake day (one month). Further the modification in GPS signal path is observed by counting the total number of satellite passes registered by the receiver (in other way, it is to estimate the Field Of View, FOV of the receiver) for the same period. In order to investigate that the modification in the GPS signal is caused due to sudden changes in atmospheric refractivity, its profile is obtained from the radiosonde observations.

\section{Data and Analysis}

The TEC data are collected by a GPS receiver at Surat $\left(21.16^{\circ} \mathrm{N}, 72.78^{\circ} \mathrm{E}\right)$ and IGS station Lucknow $\left(26.91^{\circ} \mathrm{N}\right.$, $80.95^{\circ} \mathrm{E}$ ) available in RINEX Format. We select Lucknow station as it is one of the IGS station around the fault line of the Iran earthquake (shown in the Map of Figure 1). In order to attempt to identify earthquake-induced imprints on TEC profiles, it is necessary to have knowledge on the relation of TEC with solar and geomagnetic parameters; we show in Figure 2 the variation in Dst-index for the month of April 2013. It is observed that the Dst-index did not vary throughout the observation period and so the geomagnetic condition is quite. Also the $\mathrm{F}$ 10.7 did not show much variation and its value represents a medium solar activity. Under quite geomagnetic condition the variation in TEC could be attributed to the earthquake preparation. The vertical TEC were calculated first as explained in [14]. In the second step the percentage deviation from the monthly mean was calculated:

$$
\triangle T E C=100\left(T E C-T E C_{a v}\right) / T E C_{a v}
$$

as a background level $T E C_{a v}$ the monthly mean was taken for the month of April 2013, every hour of UT.

The Atmospheric profiles for Temperature, Pressure and Humidity are derived from the measured data at given station for different altitude from the radiosonde balloon. These data are available at

http://weather.uwyo.edu/upperair/sounding.html. Radiosonde observations are a key data set in operational weather forecasting and upper air climate research. Due to their global distribution and high vertical resolution radiosonde observations have also been used for calibration and validation of satellite temperature and water vapour retrievals [15]-[17].

In the present paper the variations in refractivity profile $d N / d h$ are investigated using radisonde balloon measurements of Temperature, Pressure and Humidity from two different stations, Shiraz in Iran and New Delhi in India, along the faultline of the Iran-Pakistan border earthquake (see yellow dots in Figure 1). 


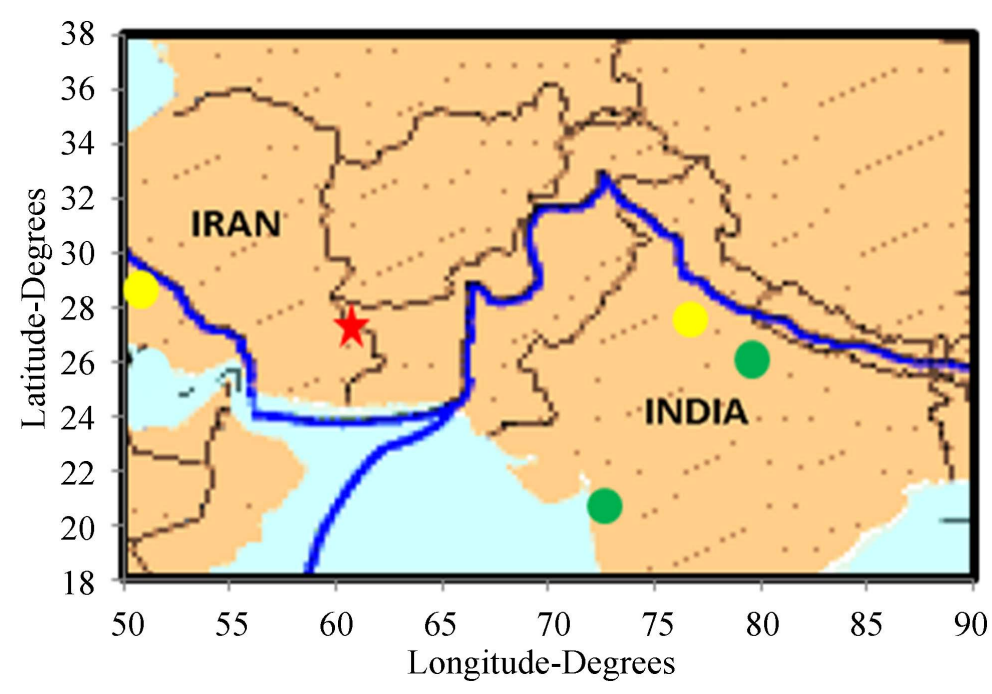

Figure 1. Show the Map of the faultline (blue line) of the Iran earthquake. The red star indicates the epicenter and the yellow and green circles show the radiosonde and GPS stations. Both the radiosonde stations are very close to the faultline and so can be the best choice to study the atmosphere around the faultline prior to an earthquake.

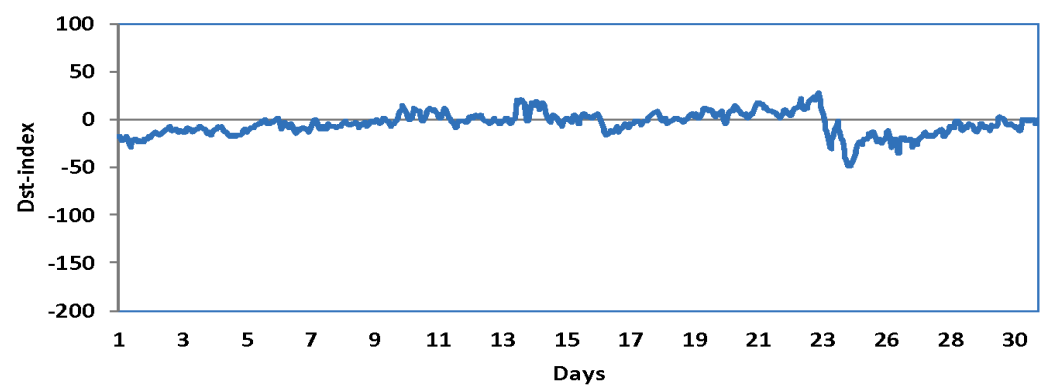

Figure 2. Dst-index for the month of April 2013.

\section{Results and Discussions}

Figure 1 shows the Map of the faultline (blue line) of the Iran earthquake. The red star indicates the epicenter and the yellow and green circles show the radiosonde and GPS stations. Both the radiosonde stations are very close to the faultline and so can be the best choice to study the atmosphere around the faultline prior to an earthquake. Both Lucknow and Surat TEC have shown some variations prior to the earthquake (see Figure 3(a) and Figure 4(a)). The percentage deviation $\triangle T E C$ from the monthly mean are presented in Figure 3(b) and Figure 4(b) for both the stations Lucknow and Surat respectively. It is seen that percentage deviation for Lucknow reaches up to $100 \%$ on 9 April and 15 April that is 7 and 1 day prior to the main shock on 16 April. However, the percentage deviation for Surat TEC is up to $60 \%$ which may be due to its distance from the faultline.

The troposphere modifies the propagation of VHF ray paths [18] through variations in the refractive index $\mathrm{n}$. In a normal troposphere condition where $\mathrm{n}$ decreases monotonically with height $(\mathrm{h})$ radio rays are slightly refracted towards the surface of the Earth. The ray path thus takes on a curvature $C=-d n / d h$. The bending of a ray relative to the Earth's surface is therefore $C-(1 / a)$, where " $a$ " is the radius of the Earth. As ray curvature $C$ changes with refractive index gradient, its relation with earth's curvature does also change and therefore the concept of "effective earth's radius" ae is introduced and ratio of effective to true earth radius is given by:

$$
K=\frac{a e}{a}=\frac{1}{\left(1+a \frac{d n}{d h}\right)}
$$




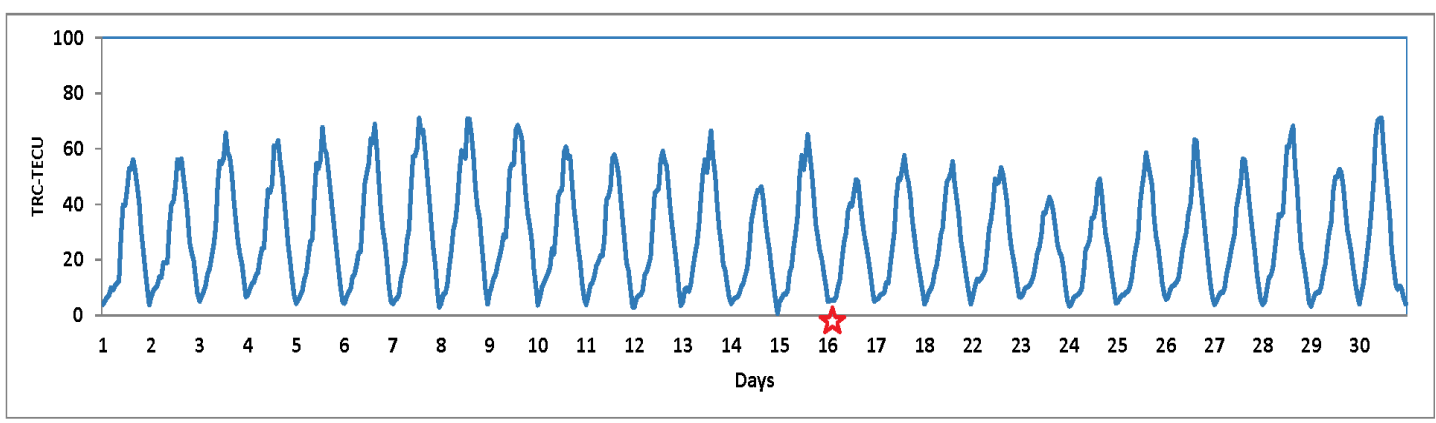

(a)

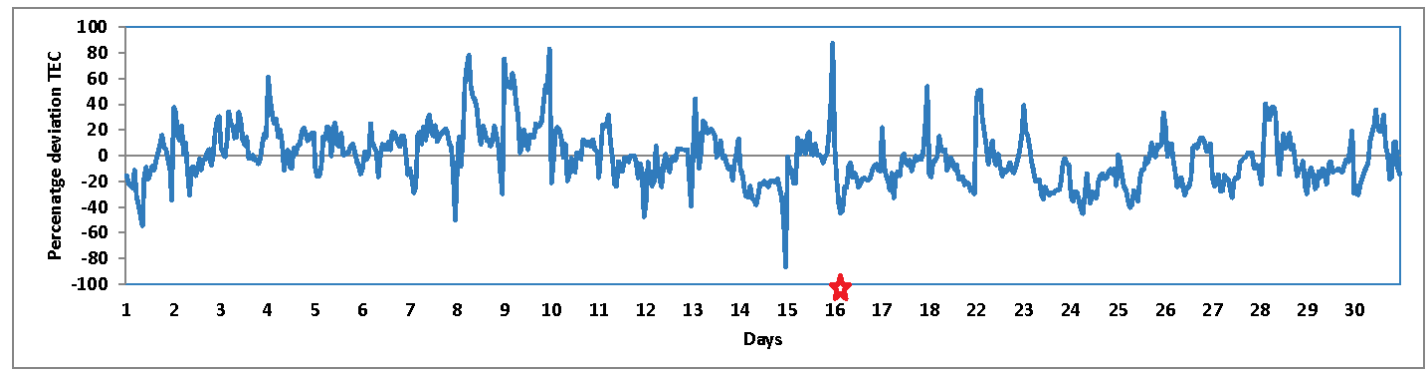

(b)

Figure 3. (a) The daily TEC variation for the month of April 2013 obtained at Lucknow station; (b) Percentage deviation in TEC from monthly mean for Lucknow station. Star indicates the Earthquake day.

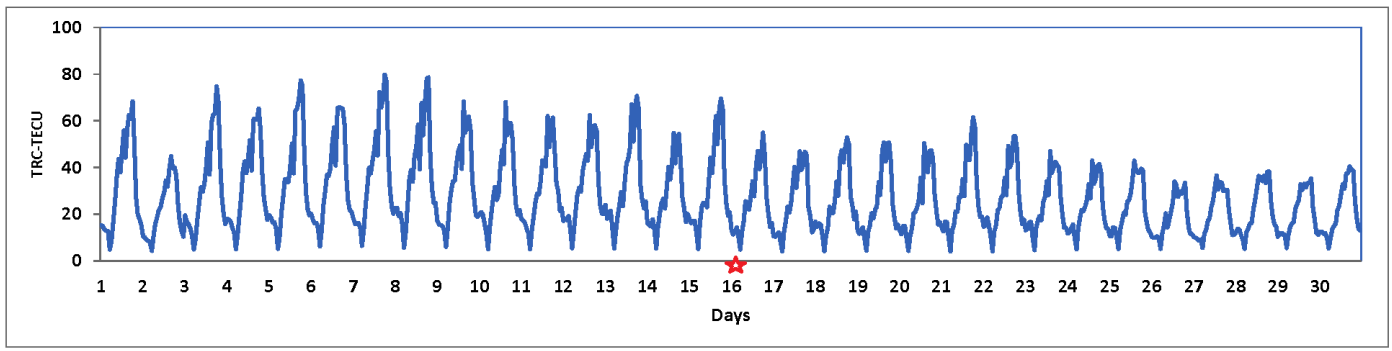

(a)

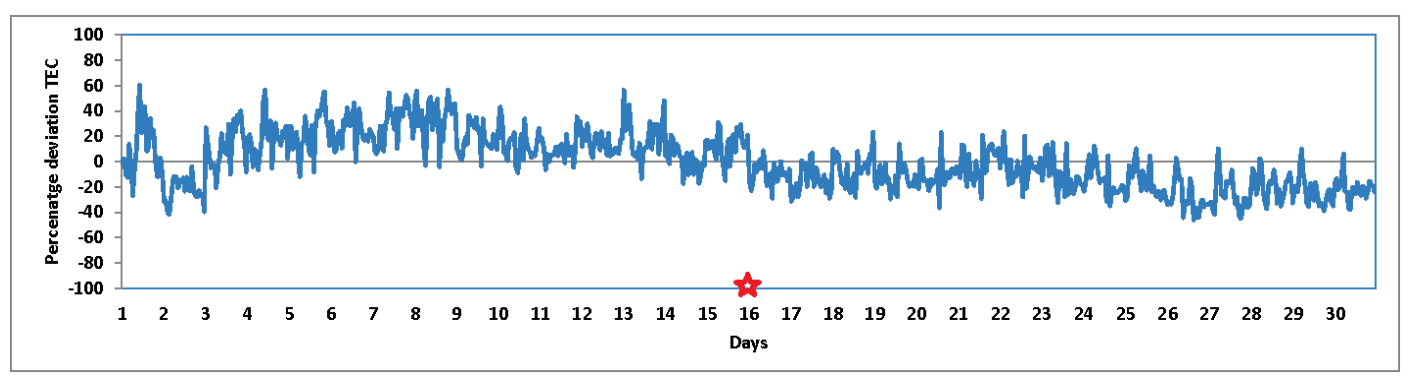

(b)

Figure 4. (a) The daily TEC variation for the month of April 2013 obtained at Surat station; (b) Percentage deviation in TEC from monthly mean for Surat Station. Star indicates the Earthquake day.

Generally, in the communication field $d n / d h$ is expressed by a parameter known as the Radio refractive Index, RRI $=N$ given by:

$$
\left[N=(n-1) \times 10^{6}\right]
$$

The relation of $N$ with temperature, pressure and water vapor is expressed as [19]: 


$$
\frac{d N}{d h}=77.6\left[\left(\frac{1}{T}\right) \frac{d P}{d h}-\left\{\left(\frac{P}{T^{2}}\right)+\left(9620 \frac{e}{T^{3}}\right)\right\} \frac{d T}{d h}+\frac{4810}{T^{2}}\left(\frac{d e}{d h}\right)\right] \mathrm{m}^{-1}
$$

For a normal lapse rate $d N / d h=-40 \mathrm{Km}^{-1}$ and $\mathrm{K}=4 / 3$, this factor defines a standard field of view of line of sight propagation links. For any change in $d N / d h$ from the above value results in increase or decrease of such path link hops [18]. Modification in $d N / d h$ values is probable at the time of impending earthquake as release of heat, if any, in the earthquake preparatory processes could reduce normal lapse rate on $d T / d h$ and so the second term of equation (4) becomes less negative. This makes $d N / d h$ more negative compared to normal lapse rate. A critical condition occurs when $d N / d h=-157 \mathrm{Km}^{-1}$ making $C=1 /$ a, i.e., the earth appears as a flat surface to the ray path thereby increasing the line of sight radio horizon. Further when $d N / d h$ becomes $<-157 \mathrm{Km}^{-1}$, the ray takes a guided path. This explains why a large number of satellites (beyond the standard LOS) are seen by the receiving antenna for elevation of zones covering $10^{\circ}-30^{\circ}$. Now, to understand why an earthquake precursory signature on radio refractive index should exceed the critical limit of $-157 \mathrm{~km}^{-1}$ one needs to understand the role of Earth's surface in the heat exchange processes. As mentioned in Devi et al. [20] the Earth's surface act as a catalyst of energy exchange processes with the near-Earth environment, the troposphere. In order to understand the heat exchange processes, the changes in specific latent heat flux (SLHF) were evaluated prior to the Earthquake [21]. They found an area of enhanced SLHF very close to the epicenter. A significant amount of work has been done associating modifications observed in SLHF, SST and water vapour to an impending EQ Singh et al. [22] [23]. These changes suggest the existence of interactions between the lithosphere and the troposphere. Ozounou et al. [24] mentioned that the processes nearest to the ground surface observed in atmosphere are the changes of air humidity and temperature. Further they explain that because gas/radon is emitted from underground, the increase of the temperature is marked immediately on the ground surface. Temperature difference between faults area and far from the faults leads to horizontal air movements, air mixture and air temperature rise over all earthquake preparation area. The relative humidity drop often accompanies it: water vapor attachment to the ions decreases the content of free water vapor in air. This may lead to a modification in atmospheric refractivity above the epicenter region and subsequently decreases the $d N / d h$ some days prior to the earthquake.

The sounding data have been used to determine the $d N / d h$ for the stations around the faultline. The graph of $d N / d h$ vs days of the April month is obtained (see Figure 5(a) and Figure 5(b)). It can be seen that the $d N / d h$ decreased beyond the critical condition $\left(<-157 \mathrm{Km}^{-1}\right)$ for both the radiosonde stations Shiraz in Iran and New Delhi in India prior to the earthquake. This attributes to the modification in FOV (field of view) of GPS receiver at Lucknow. FOV is estimated by counting the number of satellite passes registered high TEC for different elevation (see Figure 6). It is interesting to see that the day of decrease in $d N / d h$ beyond the critical condition and

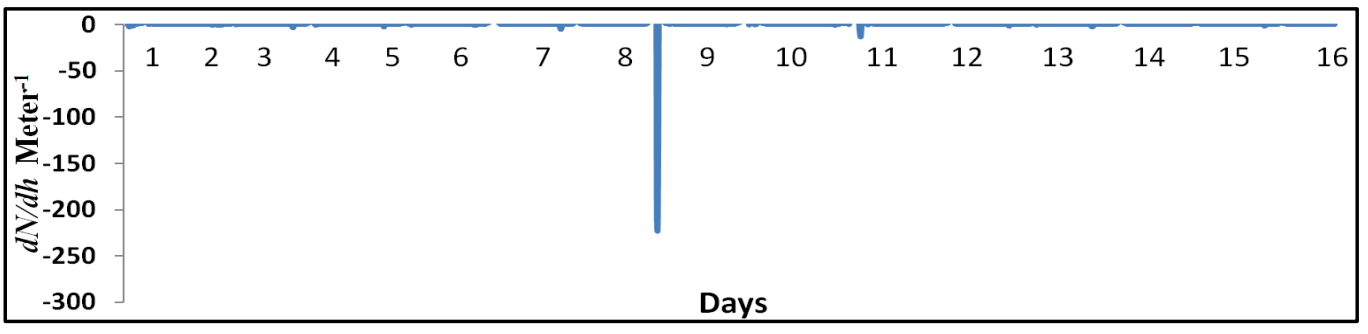

(a)

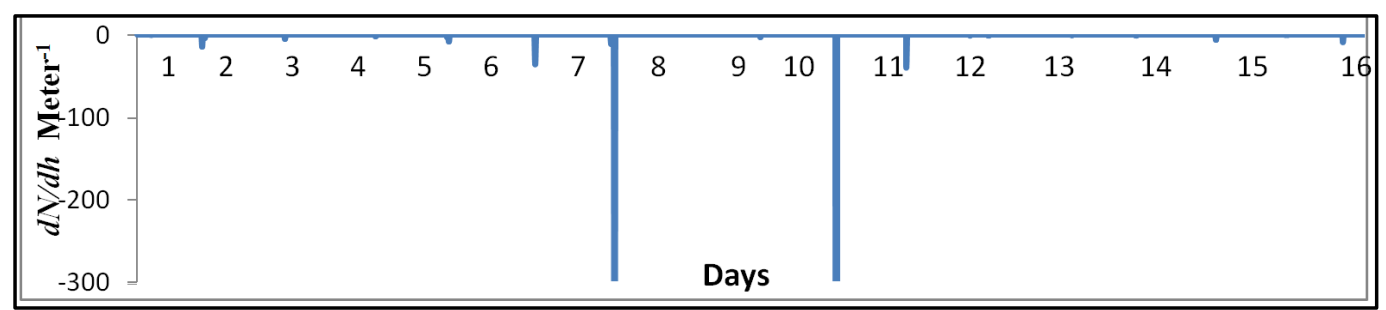

(b)

Figure 5. (a) The radio refractive index gradient $d N / d h$ for Shiraz, Iran. It is seen that the $d N / d h$ reduced beyond the critical limit $<-157 \mathrm{Km}^{-1}$ on 8 April 2013; (b) The radio refractive index gradient $d N / d h$ for New Delhi. It is seen that the $d N / d h$ reduced beyond the critical limit $<-157 \mathrm{Km}^{-1}$ on 8 and 11 April 2013. 


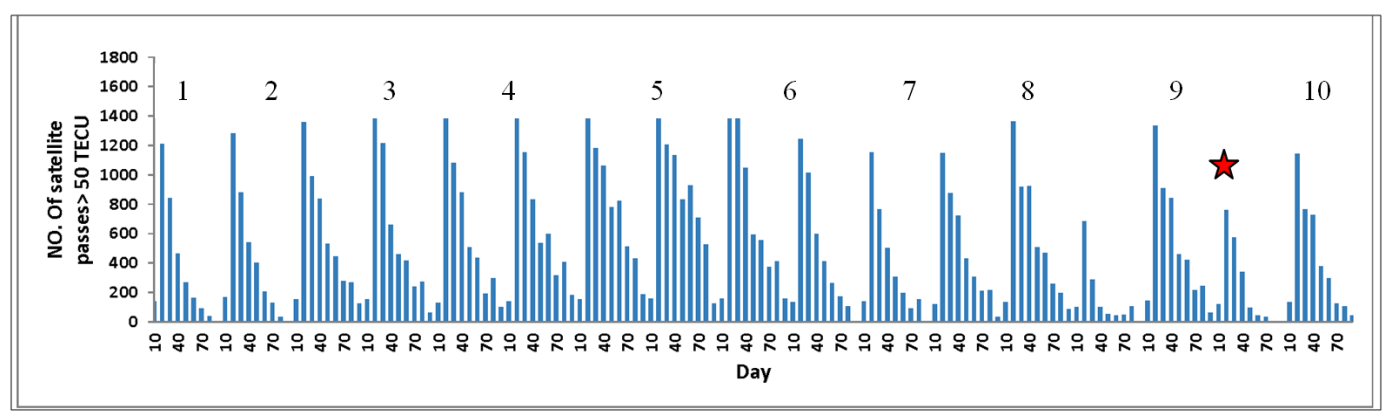

Figure 6. The change in number of satellite passes that registered higher TEC. It is observed that the GPS FOV modified on 8 April 2013. Star indicates the Earthquake day (i.e., 16 April 2013).

the day of modification in FOV of GPS receiver is same (8 April). As Lucknow and New Delhi are closer to the faultline, it is simple to depict that the modification in atmosphere around the faultline resulted in increase in FOV of the receiver. With respect to the above results from the GPS TEC data, it is seen that it may be possible to realize atmospheric changes prior to a strong earthquake within its preparatory zone through the variation in the parameters like TEC.

\section{Conclusion}

In conclusion, for the Iran earthquake, there is a visible change observed in refractivity gradient and satellite paths. However, anomaly-identifying standards should be established based on long-term regional analysis to eliminate subjectivity. Furthermore, other factors that may result in refractivity variations should also be carefully considered in order to apply these data for earthquake prediction. From the preliminary results, an association between ionospheric/atmospheric effects and its epicenter position cannot be ruled out. We can conclude that, in search of an earthquake precursory signature, atmospheric refractivity and ionospheric TEC are two important parameters.

\section{Acknowledgements}

We are thankful to the Department of Science and Technology Government of India to provide necessary funds to conduct the research.

\section{References}

[1] Liu, J.Y., Chuo, Y.J., Shan, S.J., Tsai, Y.B., Pulinets, S.A. and Yu, S.B. (2004) Pre-Earthquake Ionospheric Anomalies Monitored by GPS TEC. Annals of Geophysics, 22, 1585-1593. http://dx.doi.org/10.5194/angeo-22-1585-2004

[2] Pulinets, S. and Boyarchuk, K. (2004) Ionospheric Precursors of Earthquake. Springer, New York.

[3] Liu, J.Y, Tsai, C.H.F. and Chen, Y.I. (2001) Variations of Ionospheric Total Electron Content during the Chi-Chi Earthquake. Geophysical Research Letters, 7, 1383-1386. http://dx.doi.org/10.1029/2000GL012511

[4] Plotkin, V.V. (2001) GPS Detection of Ionospheric Perturbation before the 13 February 2001, El Salvador Earthquake. Natural Hazards and Earth System Sciences, 3, 249-253.

[5] Pulinets, S.A., Leyva, C.A., Bisiacchi-Giraldi, G. and Ciraolo, L. (2005) Total Electron Content Variations in the Ionosphere before the Colima, Mexico, Earthquake of 21 January 2003. Geofisica International, 44, 369-377.

[6] Krankowski, A., Zakharenkova, I.E. and Shagimuratov, I.I. (2006) Response of the Ionosphere to the Baltic Sea Earthquake of 21 September 2004. Acta Geophysica, 54, 90-101.

[7] Zakharenkova, E., Shagimuratov, I.I., Krankowski, A. and Lagovsky, A.F. (2007) Precursory Phenomena Observed in the Total Electron Content Measurements before Great Hokkaido Earthquake of September 25 2003. Studia Geophysica et Geodaetica, 51, 267-278.

[8] Karia, S.P. and Pathak, K.N. (2011) A Change in Refractivity of the Atmosphere and Large Variation in TEC Associated with Some Earthquakes, Observed from GPS Receiver. Advances in Space Research, 47, 867-876. http://dx.doi.org/10.1016/j.asr.2010.09.019

[9] Hayakawa, M. and Molchanov, O.A. (2002) Seismo-Electromagnetics: Lithosphere-Atmosphere-Ionosphere Coupling. Terrapub, Tokyo. 
[10] Freund, F. (2000) Time-Resolved Study of Charge Generation and Propagation in Igneous Rocks. Journal of Goephysical Research, 105, 11001-1019.

[11] Kushida, Y. and Kushida, R. (2002) Possibility of Earthquake Forecast by Radio Observations in the VHF Band. Journal of Atmopheric Electricity, 22, 239-255.

[12] Fujiwara, H., Kamogawa, M., Ikeda, M., Liu, J.Y., Sakata, H., Chen, Y.I., Ofuruton, H., Muramatsu, S., Chuo, Y.J. and Ohtsuki, Y.H. (2004) Atmospheric Anomalies Observed during Earthquake Occurrences. Geophysical Research Letters, 31, L17110. http://dx.doi.org/10.1029/2004GL019865

[13] Devia, M., Barbaraa, A.K., Depuevab, A.H., Ruzhinb, Y.Y. and Depuevb, V. (2010) Anomalous Total Electron Content (TEC) and Atmospheric Refractivity Prior to the Very Strong China Earthquake of May 2008. International Journal of Remote Sensing, 31, 3589-3599.

[14] Karia, S.P. and Pathak, K.N. (2011) GPS Based TEC Measurements for a Period August 2008-December 2009 near the Northern Crest of Indian Equatorial Ionospheric Anomaly Region. Journal of Earth System Science, 120, 851-858. http://dx.doi.org/10.1007/s12040-011-0114-1

[15] Divakarla, M.G., Barnet, C.D., Goldberg, M., McMillan, L.M., Maddy, E., Wolf, W., Zhou, L. and Liu, X. (2006) Validation of Atmospheric Infrared Sounder Temperature and Water Vapor Retrievals with Matched Radiosonde Measurements and Forecasts. Journal of Geophysical Research, 111, D09S15.

[16] Tobin, D.C., Revercomb, H.E., Knutson, R.O., Lesht, B.M., Strow, L.L., Hannon, S.E., Feltz, W.F., Moy, L.A., Fetzer, E.J. and Cress, T.S. (2006) Atmospheric Radiation Measurement Site Atmospheric State Best Estimates for Atmospheric Infrared Sounder Temperature and Water Vapor Retrieval Validation. Journal of Geophysical Research, 111, Article ID: D09S14. http://dx.doi.org/10.1029/2005JD006103

[17] Reale, A., Tilley, F., Ferguson, M. and Allegrino, A. (2008) NOAA Operational Sounding Products for Advanced TOVS. International Journal of Remote Sensing, 29, 4615-4651. http://dx.doi.org/10.1080/01431160802020502

[18] Dolukahnov, M. (1971) Propagation of Radio Waves. MIR Publisher, Moscow, 140-167.

[19] Hall, M.P. and Bradley, P.A. (1998) Troposphere and Ionosphere, Section 13. In: Mazda, F., Ed., Telecommunications Engineer's Reference Book, 2nd Edition, Reed Educational and Professional Publishing Ltd., Oxford.

[20] Devi, M., Barbara, A.K., Ruzhin, Y.Y. and Hayakawa, M. (2012) Over-the-Horizon Anomalous VHF Propagation and Earthquake Precursors. Surveys in Geophysics, 33, 1081-1106.

[21] Xu, T., Chen, Z., Li, C.B., Wu, J., Hu, Y.L. and Wu, Z.S. (2011) GPS Total Electron Content and Surface Latent Heat Flux Variations before the 11 March 2011 M9.0 Sendai Earthquake. Advances in Space Research, 48, 1311-1317. http://dx.doi.org/10.1016/j.asr.2011.06.024

[22] Singh, R.P., Bhoi, S. and Sahoo, A.K. (2001) Significant Changes in the Ocean Parameters after the Gujarat Earthquake. Current Science, 80, 1376-1377.

[23] Singh, R.P., Cervone, G., Kafatos, M., Prasad, A.K., Sahoo, A.K., Sun, D., Tang, D.L. and Yang, R. (2007) Multi-Sensor Studies of the Sumatra Earthquake and Tsunami of 26 December 2004. International Journal of Remote Sensing, 28, 2885-2896. http://dx.doi.org/10.1080/01431160701237405

[24] Ouzounov, D., Pulinets, S., Romanov, A., Romanov, A., Tsybulya, K., Davidenko, D., Kafatos, M. and Taylor, P. (2011) Atmosphere-Ionosphere Response to the M9 Tohoku Earthquake Revealed by Multi-Instrument Space-Borne and Ground Observations: Preliminary Results. Earthquake Science, 24, 557-564. http://dx.doi.org/10.1007/s11589-011-0817-z 